\title{
Supply Chain for Regional Centralized Purchasing: An Application Model
}

\author{
Alessandro Pepino, Marcella Rovani, Adriano Torri, Mario Sansone \\ Department of Biomedical, Electronic and Telecommunication Engineering, \\ University of Naples “Federico II”, Naples, Italy \\ Email: pepino@unina.it
}

Received September 3, 2012; revised October 5, 2012; accepted October 14, 2012

\begin{abstract}
In Europe Health Organizations are progressively modifying their management models to rationalize expenditure in order to assure better levels of effectiveness and efficiency: many countries are going to centralize the management of goods and services supply. In this paper a specific model of centralized purchasing is proposed; it is particularly suitable in cases of severe economy suffering at regional level (e.g. Campania, Lazio, Calabria in Italy) or at national level (e.g. Greece, Ireland, Italy), that means in all those cases where the scale economies, obtainable by supply centralization, would be partly or totally compromised by the extra charges induced by the missing of contractual commitments. This work aims either to analyse such specific approach for centralized purchasing or to propose a simulation model based on Petri net, which could be useful for designing and managing similar case studies.
\end{abstract}

Keywords: Centralized Purchasing; Workflow Management; Health Information Systems

\section{Introduction}

In the last 20 years in Europe, Healthcare Organizations are progressively integrating, at regional level, their workflows in order to guarantee adequate health services despite the limited financial resources in comparison with population healthcare needs [1,2].

Especially, many regional and national administrations aim to integrate and centralize in a single body, under public supervision, all the activities that can be assimilated each other that are normally carried out, with more expenses, by few peripheral body that in the following we indicate as "Public Health Companies" (PHC) which in general are public organizations responsible for the health services (and all the related activities) concerning one local district located within the national/regional area.

By instance, one centralized organization (normally a public company) for goods and services procurement, allows significant savings as well as good quality; therefore, in these last years, the pharmaceuticals and medical devices purchase processes have been centralized [3] either in several Italian Regions and also abroad $[4,5]$.

These centralized procurement bodies, in the most cases, are responsible just for the procurement competition, in order to increase quantities and reduce goods and service costs; the PHC remain normally responsible for the supply chain and especially for the payment to the sup- plier.

In some cases, where the PHC are not able to meet contractual commitments because their heavy debt, these central bodies keep in charge also part of the supply chain (order-invoice-payment) on behalf of the PHC in order to meet agreement payment time.

This paper describes a model of a Regional Purchasing Agency that integrally manages the whole procurement process. This paper analyses the process from the workflow point of view [6] and suggests a specific model, based on Petri Nets, in order to quantitatively outline benefits and critical points.

\section{Materials and Methods}

In the case study here presented, the Regional Purchasing Agency is responsible for drugs and medical devices purchase to be distributed among healthcare public companies responsible for the regional districts that in the following will be indicated as "PHC".

At an operative level, the workflows could be outlined as shown in Figure 1.

Periodically the Agency collects from the PHCs the data concerning the Health Regional Districts needs, and then announces the centralized procedures of bids evaluation concerning the acquisitions of required goods and services. After that, the PHC- on behalf of and through the Purchasing Agency information system-send 


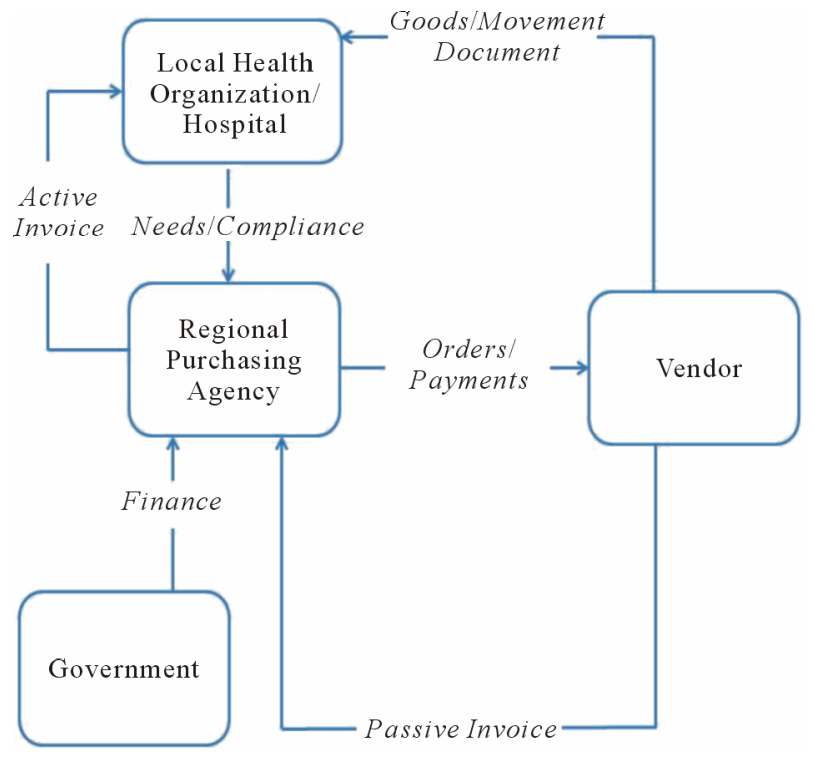

Figure 1. Regional purchasing agency workflow.

the orders to those suppliers who have been awarded, through public competition, on the basis of agreement prices and supply conditions. The Suppliers send goods and shipping documents to PHC and the corresponding invoices (that will be indicated in the following as "passive invoices”) to the Regional Agency itself. Finally the Regional Agency either provides payment to the supplier or attends to issue corresponding active invoices to the Public Health Companies, at the end of accounting cycle. The Public Health Companies will not provide any payment to the Regional Agency but they are responsible for the receipt and the logistics of supplied goods, as well as, the shipping documents checking, that is a mandatory requirement for the passive invoices' payment to the supplier.

On the basis of one specific agreement with the Regional Administration, the payment of the active invoices to the Regional Agency by PHC is made through a specific mechanism of withdrawals, from the funding that the Regional Administration periodically send to the individual PHC; this mechanism represents an essential element of guarantee for the Regional Agency and, therefore for the Creditor Suppliers, too.

This specific operating model, which is different from the one adopted by the most of the Purchase Regional Agencies in Italy, generates a duplication of the administrative flow; in fact, for any provision, two corresponding invoices must be individually processed by the Regional Agency (Public Healthcare Company <-> Regional Agency $<>$ Supplier); this peculiarity represents a critical element that necessarily imposes that the documental flow and the management model, starting from the order up to the invoice's payment, should be as much automated as possible. So, the Regional Agency has to set up an appropriate administrative information system, which should be able to manage, for a huge amount of document (200,000 order/invoice per year), the great heterogeneity of deliveries and the different invoice modalities, normally specified into the agreement with the different Suppliers.

\subsection{The Information Management System}

The Information System has to manage the whole administrative workflow; with reference to a usual accounting management system [7], it must also provide a specific set of check points and management functions related to the specific needs of the Regional Agency supply chain. The workflow reported in Figure 1 highlights the high degree of integration that is required between the information systems operating in the PHC and the Central Agency. Moreover, it also should comprise integration's modules with the local information systems handled by the individual PHC's. The PHCs are in fact responsible for the certification of good's conformity, and, in addition, must have their own independent accounting system in order to guarantee an appropriate internal management control.

So, the information system integration's modules must provide:

- The order database update to keep aligned the orders managed by the PHC and the corresponding orders generated into the Regional Agency's Centralized System.

- The shipping documents database update to keep aligned the shipping document managed by the PHC and the corresponding shipping document database into the Regional Agency's Centralized System, in order to allow the staff Agency to authorize the invoices payment.

From a technical point of view, in the Author's experience, the integration between the central information system and the PHC one, could be done by mean a simple FTP data exchange [8,9], although Web services and SOA technologies promise to be more efficient from this point of view [10].

The information system should allow the PHC operators to make via web a "proposed order", representing the Health Company's request to the Regional Agency, which then has to be confirmed before delivering to the supplier.

Normally, all these activities are carried out by PHC administrative staff under the supervision by one pharmacist/administrative belonging from the Regional Agency) in order to complete such "ordering phase".

The latter, as holder of the supply contract, sends (automatically by fax or by mail) the order to the supplier; of course, the same order, through the integration system, 
has to be exported to the PHC Information System.

The PHC operators, at the good receipt, must provide, in their information systems, the data entry concerning the details about the received products; after that these data must be exported as well, toward the Regional Agency information system.

The Regional Agency has to register the passive invoices sent by the Supplier. In principle the passive invoices recording usually requires a simple data entry concerning few key data (Figure 2).

On the other hand the generation of the active invoices requires full detail of the order rows. This means that, given the expected document volume, (200,000 documents/year), in the case of passive invoices manual data entry, this would result in a heavy workload and a potential quality data loss, such as to make the model not suitable.

If the model of e-invoicing scheme would be already gone in Italy, the problem would be already solved, but, unfortunately, most of the supplier cannot yet provide electronic invoices. One possible solution, to avoid manual data entry, is to reconstruct the details of the passive invoice document by using the data contained in the shipping document normally updated by the PHC upon receipt of the ordered goods or services.

As reported in Figure 2 on the basis of the order number and the Supplier code, it could be possible to findthrough the table of the shipping documents (CMR)the details related to the passive invoice; this mechanism therefore allows to automatically generates an "accounted

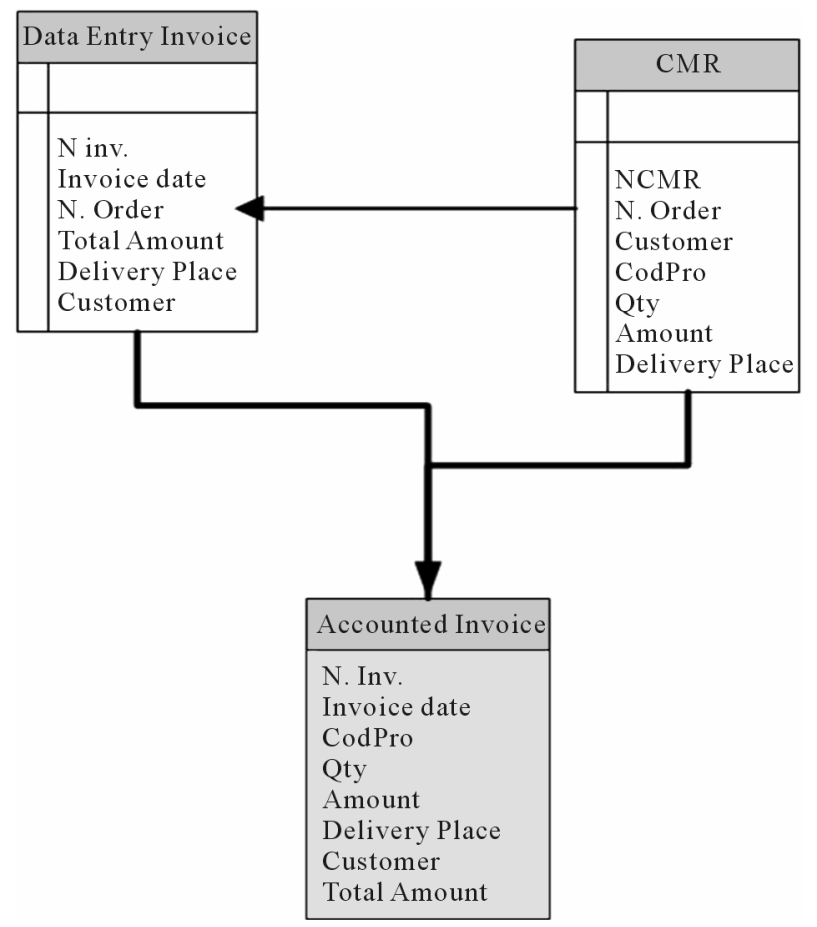

Figure 2. Invoice details reconstruction. invoice" (that is line by line coherent with the passive invoice) avoiding the manual data entry. Of course a number of checks in order to verify the exact match between the accounted invoice and the shipping document has to be done.

Unfortunately, sometimes, at the time when passive invoice is recorded in the information system, the data concerning the shipping documents are not yet available because they have not yet been inserted in the PHC's database; moreover the unit cost, or the description of the goods on the invoices maybe different from the ones contained in the shipping document, due to a database misalignment.

In such cases, the accounted invoice details must necessarily be registered manually; small differences due to numerical rounding however can be tolerated according to the limits prescribed by law; this allows to avoid, in a significant number of cases, the manual data entry and therefore it makes more efficient the operating flow.

On the basis of accounted invoice the information system should generate, through an automatic overturning, the corresponding active invoices, to be sent to the PHC, in order to be accounted in the respective budgets. The last step of the management cycle requires the comparison between the passive invoice and the shipping documents already registered into the information system, in order to authorize the payment to the supplier; in this step that is under the responsibility of the regional agency, the Regional Agency staff should check, line by line, the exact match between the ordered products, and ones delivered and billed. This activity is generally quite hardworking, but, of course, in the case that the accounted passive invoice has been generated by the automatic procedure, this check could be automatic as well. From the above, it is important, in order to reduce the workload and therefore the operating times (also for improving the overall quality of the process), to have an adequate alignment of the product codes that are used at the order's time, to ones used by suppliers.

In other words, the correct and efficient management of the entire supply chain order - DDT - invoicing - payment, generally requires an accurate alignment of data related to the product codes, with the ones reported in the order and in the invoice documents, in order to allow an easy and reliable comparison of the invoices, order and shipping document.

So, it is very important to ensure the consistency between the counterparts data provided to the following tables:

- Products code of Health Organizations,

- Providers' product code,

- Medicine and medical devices’ code,

- Contracts,

- Orders, 
- Delivery/Shipping Documents,

- Invoices.

Any misalignment between these tables may become a discrepancy or ambiguities in the comparison between the order rows and the invoices data. From this discrepancy arise both the difficulties in payment authorisation and consequently delays in completing the procedure.

\subsection{A Supply Chain Model Based on Petri Nets}

On the basis of the above steps the supply chain management should take into account a number of efficiencies/inefficiencies which arise from the workflow structure and from different actors in the process.

In order to investigate the above supply chain, and to provide a simulation tool for such organizational model that could be used also for further case studies, we have designed a workflow based process model by using the Petri nets. As shown by the literature [11] the Petri nets allow to design a process specifying the activities sequence and assigning them a duration time and the resources who are delegated to their execution.

Once the net design has been completed, some simulations can be done to reproduce the process behaviour in different conditions, in order to highlight the critical issues.

Figure 3 shows a Petri net, based on the operative steps above outlined, that, without any claim of completeness, allows to simulate the main critical elements of the supply chain workflow concerning the Regional Purchasing Agency.

Following the Petri net's rules the network's token represents, within the workflow, the document of order/ delivery/invoice; in particular, it is assumed that one token corresponds to n. 200 orders/shipping documents/ invoices. In these circumstances the flow starts with the order generation by PHC (through Regional Purchasing Agency Information System). These orders will be below indicated as OA. They are then forwarded by the Regional Purchasing Agency to the Suppliers through the generation of a further document which will be indicated as OF (Figure 4). The Suppliers deliver the required products, with the relative shipping documents, directly to the PHC Thus, the latter must manage the logistic activities that are necessary for the distribution to the destination PHC departments and must verify the conformity of the receipt goods. Once the order has been sent to the supplier, the workflow provides (AND split) two distinct parallel branches: the first, who belongs to the Agency for the management of the passive and active invoices (Figure 5); the second who belongs to PHCs, who have in charge the logistics, that includes the management of the shipping documents (Figure 6).

This second branch provides also-on the basis of what really happens-two alternatives: in one case the goods and the shipping documents are regularly and quickly handled, (CMR collect branch); instead, in the other case, the shipping documents-because a number of reasons related to the inefficiency of the healthcare companies' logistic network-follows an alternative path where the same activities are carried out in a much longer time (CMR Lost branch). The two branches are then joined by an AND join that simulates the positive check of compliance necessary for the invoice payment (Paym chk).

The invoicing process involves sequentially the recording of the passive invoices sent from the Supplier to the Regional Agency, then the generation of an active invoice from the Regional Agency to the PHC who performed the order. The model provides that all these activities may happen in a manual or automatic mode: in the first case the registration of the individual rows of the invoice must be performed through a manual data entry; in the second, assuming that both the order and the shipping document are available in electronic format, the reconstruction of the individual rows of the invoice can occur automatically (Figure 5). Then, the correct handling of the shipping documents is involved in the process at two levels: directly regarding to the compliance

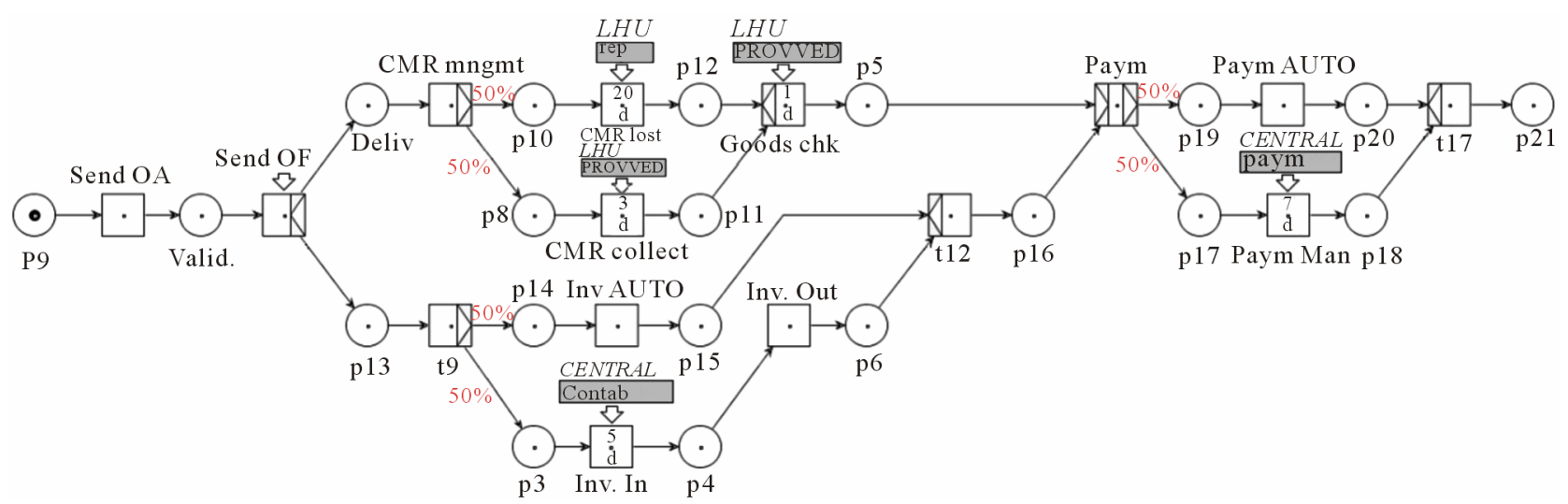

Figure 3. Complete petri net. 


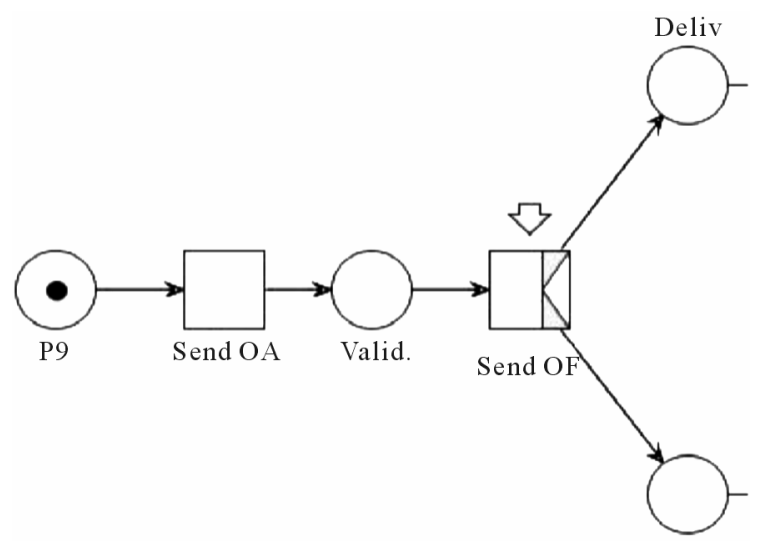

Figure 4 Ordering phase.

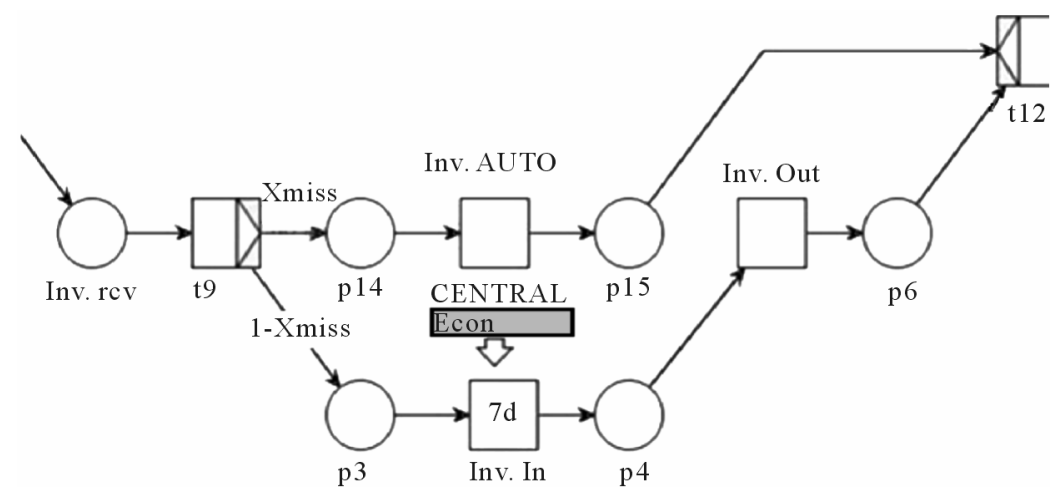

Figure 5. Invoicing management.

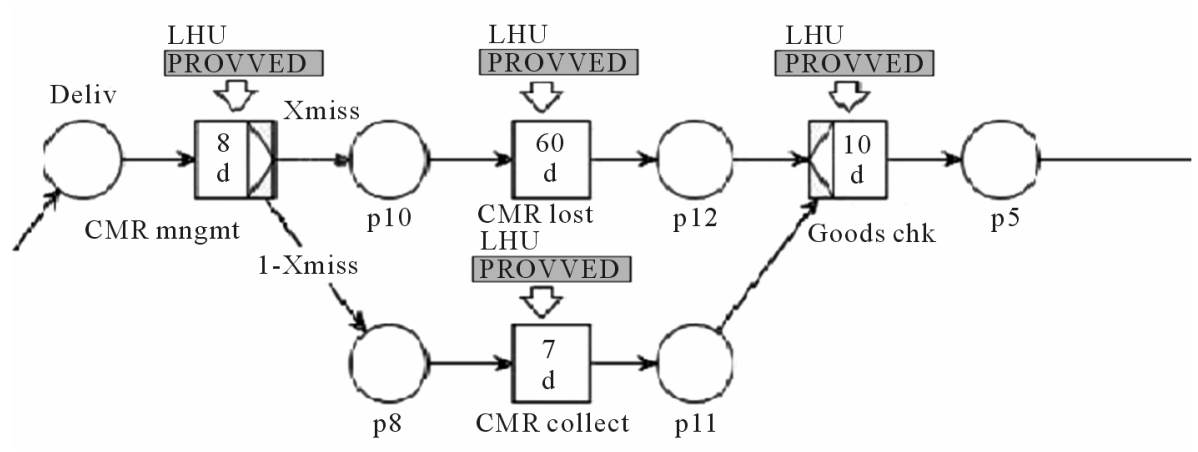

Figure 6. Shipping document management.

check, and indirectly through the ability to automate the passive and active invoices' rows entry in the information system.

Similarly, a last segment of the model simulates the payment authorization process: it can be carried out manually - through the manual verification rows by rows of the shipping document associated with the order-or automatically, thanks to invoice reconstruction above detailed (Figure 7). Because the automatic invoice management depends on the number of shipping documents in time recorded, all these different operating situations are represented, within the model, through a series of "xor" transitions that shunt, alternately, in appropriate branches the token on statistical basis, depending on the percentage of transport document which have been properly handled (X.miss).

In order to have workflow simulation, each transition of Petri Net must be configured with the associated resources. For the model configuration - as shown in the Table 1-the data to be measured on the real system are, therefore:

1) X.miss: percentage of documents managed with considerable delay, that is conventionally assumed equal to 20 days instead of 3 days;

2) N. Inv: n. purchasing staff unit of the Regional Pur- 


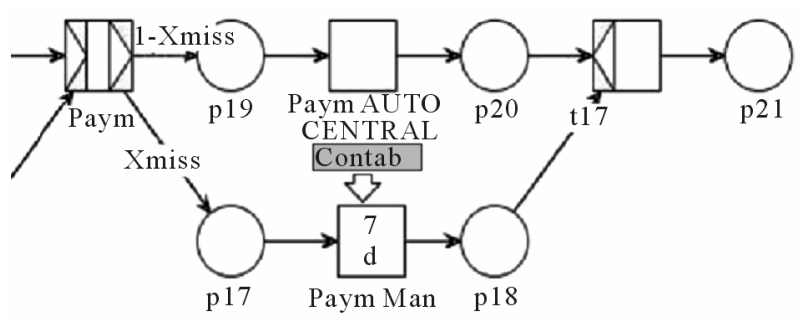

Figure 7. Payment authorization phase.

chase Agency responsible for invoices and payments management;

3) T. Inv: Time required to load 200 passive invoices by a personnel unit; this data is conventionally fixed equal to 5 days/staff unit;

4) N. Paym: N. Agency's staff unit responsible for managing invoices and payments;

5) T. Paym: Time required for authorize the payment of 200 passive/active invoices by one staff unit; this data is conventionally fixed at 7 days/staff unit;

6) N. cmr: N. of PHC's unit responsible for shipping documents managing;

7) T. cmr 1: Average time of management's collection of shipping documents (great channel); relating to 200 invoices/ shipping documents, this data is conventionally fixed equal to 7 days/staff unit;

8) T. cmr 2: average time of management's collection of shipping documents (delayed channel); referring to 200 invoices/shipping documents; this data is conventionally fixed equal to 20 days/ staff unit;

9) T. cmr 3: Average time of compliance verification's management; referring to 200 invoices/shipping documents this data is conventionally fixed equal to 1 day/ staff unit.

It should be pointed out that while the values 1), 2), 3), $4), 5)$ are determined on the basis of authors' experience inside one regional agency's activities, the setup of 6), 7), 8), 9) should be done on the basis of PHC's indication concerning the specific case study.

Anyway, a more accurate estimation of this information would not change significantly the model. In the tab. 1 are listed the values so assigned to the configuration's parameters.

It is interesting to analyse the model's behaviour as a function of the parameters on which the Regional Purchasing Agency has some responsibility. We consider that the Regional Agency's management could change "N. inv" or on "N. Paym" increasing the staff for invoice recording and payment authorisation. Alternatively, it would be also possible to modify "X.miss", through appropriate actions on the PHC management in order to ask them more attention about the shipping document management. About all the other parameters, conversely, it's far more complex to step in, because they are completely under the responsibility of the PHC Administration.

\section{Results \\ Quantitative Analysis}

By using the Woped analysis tool we aim to demonstrate what are the strengths and the weakness characterizing the workflow model designed for Regional Purchasing Agency PHC. Such inefficiencies, especially referring to the shipping document's management, therefore influences the entire operative workflow. The workflow model has been designed by the open source software www. woped.org [12]; the related file is attached to this paper. Into the Woped quantitative analysis menu, by setting the parameters of resources' flow and productivity referred to point 1) to 7), it is possible to evaluate the workflow duration which could be considered as the payment time "p. delay", that represents one major priority of a Regional Agency that carries out the central role of payment.

In particular, our analysis, evaluates the trend of the "p. delay" as a function of the following variable elements:

1) percentage of missed shipping documents "X.miss";

2) amount of resources used for the invoices and payment management "n paym", "n. inv".

In the Table 2 they are listed the parameters required by the software simulation with reference to the presumed work volume.

As far as the point 1 , we report on the Table 3 and in the Figure 8 the results obtained by some simulations performed considering different values assigned to the percentage of "X.miss" (missed shipping documents).

As expected, the payments timing is drastically reduced by the "X.miss" reduction of thanks to the consequence of the accounting workflow automation improvement; this aspect is expressed in the corresponding branches in the model marked with (X.miss - 1). It

Table 1. Configuration parameters.

\begin{tabular}{lccc}
\hline & Min. Value & Max Value & Fixed Value \\
\hline X.miss & 10 & 90 & \\
N. inv & 4 & 9 & \\
N. cmr & & & 12 \\
N. paym & 4 & 6 & \\
T. inv & & & 5 days \\
T. paym & & & 5 days \\
T. cmr1 & & 7 days \\
T. cmr2 & & 20 days \\
T. cmr3 & & 1 day \\
\hline
\end{tabular}


Table 2. Simulation parameters.

\begin{tabular}{cc}
\hline Value of each token & $\mathbf{2 0 0}$ \\
\hline Number of token in one simulation & 1000 \\
Invoces number & 200,000 \\
Observation period & 1 year \\
Time unit & 1 day \\
\hline
\end{tabular}

Table 3. Payment delay vs X.miss.

\begin{tabular}{cc}
\hline X.miss \% & P. Delay (day) \\
\hline 90 & 2279.05 \\
80 & 590.67 \\
70 & 251.84 \\
60 & 165.84 \\
50 & 103.19 \\
40 & 71.29 \\
30 & 70.22 \\
20 & 60.65 \\
10 & 74.63 \\
\hline
\end{tabular}

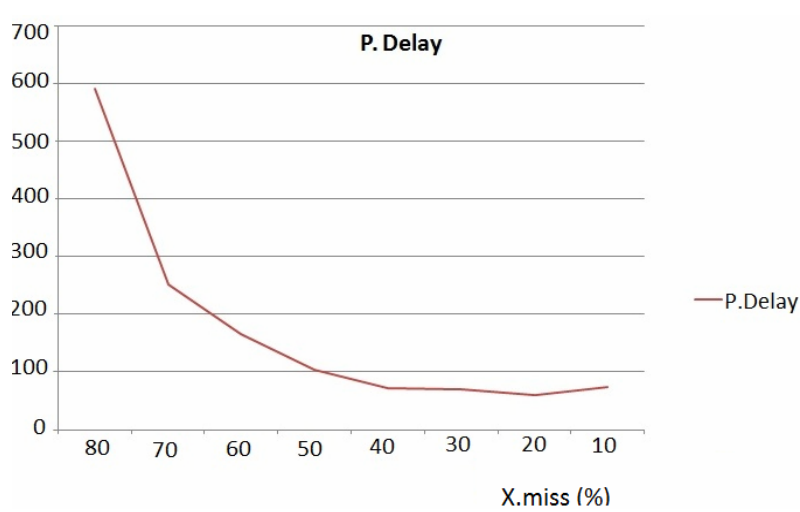

Figure 8. Payment delay respect to the shipping document leackage.

should be considered, however, on the basis of the real experience-that it is not easy-relay on a reduction of "X.miss" < 50\%; therefore, it was made a second simulation in which the percentages of the xor branches it has been assigned a value of "X.miss" equal to $50 \%$.

So, the simulations were carried out according to the data of the Table 4. In this simulation, given the value of X.miss $=50 \%$ the payment time is calculated, firstly by increasing ( $\mathrm{N}$. inv $=4$ to 9 ) the resource staff who is responsble for the invoices management; then by sharing the same resources for the payment authorization (in order to keep to a fixed value the global amount of staff resource “Tot Res = 13"). In such way, we got a delay time
Table 4. Trend of the payment times given the value of X.miss $=\mathbf{5 0} \%$ for different values of $\mathrm{N}$. inv and N. Paym.

\begin{tabular}{lcccc}
\hline & $\begin{array}{c}\text { P. delay } \\
\text { (day) }\end{array}$ & N. inv & N. paym & Tot Res \\
\hline 112 & 4 & 4 & 8 \\
& 100 & 5 & 4 & 9 \\
$\mathbf{X . m i s s}$ & 76 & 7 & 4 & 11 \\
$\mathbf{5 0 \%}$ & 67 & 8 & 4 & 12 \\
& 66 & 9 & 4 & 13 \\
& 43 & $8+1$ & $4+1$ & 13 \\
& 33 & $7+2$ & $4+2$ & 13 \\
& 32 & $6+3$ & $4+3$ & 13 \\
\hline
\end{tabular}

for payments equal to just 32 days that would be absolutely satisfactory for normal use.

Of course, all these results are just an indication about how the payment delay are related to the resource amount and do not take into account any additional delays due to the relationships with banks or with the regional administration. The simulation values emerging from the simulation are however consistent with the data coming from the field experiences.

\section{Discussions}

The Regional Centralized Agency guarantees significant savings in health service and goods purchasing. The supply chain management requires a specific ICT based organisation and workflows. Because of the sharing of supply chain responsibility between the Regional Agency and Health Companies, there are some critical issues that have to be managed.

A strict level of automation and integration with the PHC is required, in order to guarantee a real-time transfer of accounting documents, as well as a perfect alignment of accounts in order to avoid inconsistencies between order/invoice/shipping documents/invoices that would have serious rebound on the invoices' settlement. A workflow model representing some characteristic behaviours of a Regional Agency workflow is suggested: in particular it allows to analyze the performance of the system according to some critical features of this type of Agency. The model simulation shows how important is a correct management of the logistic related to the goods delivery in order to ensure a timeline data entry of the shipping documents in the information system; in fact, the payment delay due to a feckless shipping documents management (X.miss $\gg 50 \%$ ), resulted unacceptable. Therefore the management of a Regional Agency re- 
quires a strong control over PHC, which has the responsibility of both the receipt and the verification of the delivery goods' conformity. Given an average amount of delayed shipping document $(\mathrm{X}$.miss $=50 \%$ ) and given $\mathrm{a}$ productivity approximately around 800 invoices per month for each personnel unit, (including invoices and payment management) it would be possible, with approximately 13 personnel units, (where at least 9 of them have to be shared between "invoice registration" and "payment authorization" role), to manage a flow of about 200,000 invoices/years, guaranteeing an average time for the accounting flow equal to about 30 days.

Although many information related to this model's structure have been derived from the field experience this model could be used also for other similar case studies Unfortunately some factors having a certain degree of randomness, should be taken into account for example:

- The presence of electronic invoicing flows (that, because of national policies costraints, must be considered residual respect to the ordinary invoice flows).

- Other automatism and specific aspects of the management software.

- The Personnel turn-over with relative training aspects.

\section{Conclusion}

In conclusion, a regional purchasing agency also playing the role of payment central, because determines an additional level in the supply chain management requires much attention about logistics and the conformity verification of received goods, management, by PHC, who are the final recipients of those provisions and responsible for that. The logistic weakness by PHC resulted in more staff necessity for the Regional Agency in order to guarantee the appropriate document management. By using the proposed model it some general assessments could be done: about the balance between the shipping document, dispersion index, and the amount of additional administrative staff to be employed in The Regional Agency staff to manage the documental flow. In other words, starting from the document flow size, and the X.miss index it is possible to determine the personnel quantity that is necessary to guarantee the requested payment delay.

\section{Acknowledgements}

This work was supported in part by the scholarships for the Ph.D. project in "Economics and Management of Healthcare Companies and Organizations”.

\section{REFERENCES}

[1] B. Abel-Smith and E. Mossialos, "Cost Containment and Health Care Reform: A Study of the European Union," Health Policy, Vol. 28, No. 2, 1994, pp. 89-132. doi:10.1016/0168-8510(94)90030-2

[2] M. Amatucci and S. Mele, "Centralized Purchasing in Healthcare: A Comparison between National and International Experiences," 15th Annual Conference AIES of the future Healthcare: Institutions, Efficiency and Equity, Moncalieri, 30 September-1 October 2010.

[3] B. Tony, "Developing New Forms of Partnership With the 'Market' in the Procurement of Public Services," Public Administration, Vol. 84, No. 1, 2006, pp. 81-102. doi:10.1111/j.0033-3298.2006.00494.x

[4] E. Bakker, H. Walker, F. Schotanus and C. Harland, "Choosing an Organizational Form: The Case of Collaborative Procurement Initiatives,” International Journal of Procurement Management, Vol. 1, No. 3, 2008, pp. 297-317. doi:10.1504/IJPM.2008.017527

[5] T. P. Lyon, “J. J. Laffont and J. Tirole, A theory of incentives in regulation and procurement," Information Economics and Policy, Vol. 6, No. 1, 1994, pp. 89-93. doi:10.1016/0167-6245(94)90038-8

[6] W. van der Aalst and K. van van Hee, "Workflow Management: Models, Methods, and Systems,” MIT Press, Cambridge, 2004.

[7] C. J. Austin, J. M. Trimm and P. M. Sobczak, "Information Systems and Strategic Management,” Health Care Management Review, Vol. 20, No. 3, 1995, pp. 26-33.

[8] B. Forouzan, Ed., “TCP/IP Protocol Suite,” McGraw-Hill, New York, 2002.

[9] D. Parker, “Understanding the FTP Protocol,” 2005. http://www.windowsnetworking.com/articles_tutorials/un derstanding-ftp-protocol.html?printversion

[10] F. Curbera, M. Duftler, R. Khalaf, W. Nagy, N. Mukhi and S. Weerawarana, "Unraveling the Web Services Web: An Introduction to SOAP, WSDL, and UDDI," IEEE Internet Computing, Vol. 6, No. 2, 2002, pp. 86-93. doi:10.1109/4236.991449

[11] W. M. P. van der Aalst, "The Application of Petri Nets to Workflow Management,” Journal of Circuits Systems and Computers, Vol. 8, No. 1, 1998, pp. 21-66.

[12] T. Freytag and S. I. Landes, "PWFtool-A Petri Net Workflow Modelling Environment," 11th Workshop on Algorithms and Tools for Petri Nets (AWPN), Eichstätt, 30 September-1 October 2004. 